\title{
Highly conductive ruthenium oxide thin films by a low-temperature solution process and green laser annealing
}

Yoshitaka Murakami ${ }^{1,2, *}$ Jinwang $\mathrm{Li}^{1,3, *}$ Tatsuya Shimoda ${ }^{1,3,4}$

${ }^{1}$ Green Devices Research Center, Japan Advanced Institute of Science and Technology (JAIST),

2-13 Asahidai, Nomi, Ishikawa 923-1211, Japan

${ }^{2} J S R$ Corporation, Yokkaichi Research Center, 100 Kawajiri-cho, Yokkaichi, Mie 510-8552,

Japan

${ }^{3}$ Japan Science and Technology Agency (JST), ERATO, Shimoda Nano-Liquid Process Project,

2-5-3 Asahidai, Nomi, Ishikawa 923-1211, Japan

${ }^{4}$ School of Materials Science, Japan Advanced Institute of Science and Technology (JAIST), 1-1

Asahidai, Nomi, Ishikawa 923-1292, Japan

\begin{abstract}
Highly conductive ruthenium oxide $\left(\mathrm{RuO}_{2}\right)$ thin films were prepared by a low-temperature solution process combined with green laser annealing (GLA). The process allowed production of $\mathrm{RuO}_{2}$ films at a low temperature of $250^{\circ} \mathrm{C}$. GLA led to effective sintering of the film, significantly improving crystallinity and film density and resulting in joining between grains, and consequently, the conductivity was dramatically increased by one order or more. The $\mathrm{RuO}_{2}$ thin films show a low resistivity (e.g., $7.6 \times 10^{-5}$ $\mathrm{cm}$ for a $40 \mathrm{~nm}$-thick film), which was approximately 2 times of that of the single crystal $\mathrm{RuO}_{2}$. Such resistivity has not been achieved only by thermal annealing, even at a high temperature of $800^{\circ} \mathrm{C}$, after solution deposition, and is similar or lower to that of vacuum-deposited $\mathrm{RuO}_{2}$ films.
\end{abstract}

Keywords: Conductive film, solution process, ruthenium oxide, laser annealing, low temperature process

Corresponding Author. E-mail address: Yoshitaka_Murakami@jsr.co.jp (Yoshitaka Murakami), lijw@jaist.ac.jp (Jinwang Li). 


\section{Introduction}

Ruthenium oxide $\left(\mathrm{RuO}_{2}\right)$ is an attractive candidate material for electrodes in memory devices and transistors owing to its relatively low resistivity $\left(3.6 \times 10^{-5} \mathrm{~cm}\right.$ for single crystal) [1] and high stability, as well as its high work function $(\sim 5 \mathrm{eV})$ and good susceptibility to dry etching. In our study on printed oxide electronics, $\mathrm{RuO}_{2}$ has turned out to be an excellent printable material with both high conductivity and high chemical stability that can be processed in an ambient atmosphere [2]. In the study, we investigated a variety of conductive materials for our newly developed printing method (nano-rheology printing or $\mathrm{nRP}$ ) [2], and found that the common conductors suffer various problems. For example, $\mathrm{Cu}$ suffers from oxidation during processing of subsequent oxide layers in air, $\mathrm{Ag}$ has a low interface adhesion to adjacent oxide layers, $\mathrm{Al}$ cannot be produced by a printable precursor, and Pt still cannot be patterned by $n R P$.

The most commonly used routes for the fabrication of $\mathrm{RuO}_{2}$ thin films have been sputtering $[3,4]$, chemical vapor deposition $[5,6]$, and atomic layer deposition $[7,8]$. However, these vacuum-deposition methods require expensive equipment, and therefore the manufacturing costs are high. As an alternative method, solution processes have various advantages including fast processing, simple and low-cost equipment, the ability to fabricate films with large areas, and applicability to printed electronics [2]. Despite the benefits of low cost and fast processing, the solution preparation of high-quality $\mathrm{RuO}_{2}$ films has gained little progress in the last decade [9,10]. Very recently, we have developed an amine-complex-based solution process that enables nRP patterning of $\mathrm{RuO}_{2}$ [11]. These processes commonly require high annealing temperatures over $400^{\circ} \mathrm{C}$ to decompose the precursors and to densify the films. Even so, the effect in reducing resistivity is small by thermal annealing (e.g., from $3.1 \times 10^{-4}$ $\mathrm{cm}$ at $400^{\circ} \mathrm{C}$ decreased to $1.8 \times 10^{-4} \mathrm{~cm}$ at $800^{\circ} \mathrm{C}$ ) [10] because $\mathrm{RuO}_{2}$ is highly thermally stable and the densification via solid diffusion in conventional heating is very slow. In addition, the high annealing temperature can cause damages of other parts (e.g., plastic substrates and silicon circuits) during device fabrication. 
In laser annealing, the sample surface or film can be locally heated to a temperature high enough for fast sintering while the bulk of the sample or the substrate (e.g., a polymer substrate) maintains at a low temperature. The excimer laser annealing (ELA) process has been utilized to achieve a low-temperature process of silicon and metal oxide transistors [12]. As an alternative of laser annealing, green laser annealing (GLA), which uses all-solid-state laser, is an attractive candidate owing to its low maintenance cost, stable laser power and a large process window [13]. There have been several reports on the utilization of GLA technique for metal oxides [14]. For solution processing of $\mathrm{RuO}_{2}$, use of laser irradiation to decompose the dried (below $100^{\circ} \mathrm{C}$ ) precursor films into $\mathrm{RuO}_{2}$ films has been reported [15], but the resultant films had resistivity values $\left(\sim 4 \times 10^{-3} \mathrm{~cm}\right)$ similar to those of typical thermally decomposed ones at low temperatures (below $300^{\circ} \mathrm{C}$ ), indicating the laser irradiation did not resulted in sintering of the films.

The solution process we developed allows low-temperature preparation (below $300^{\circ} \mathrm{C}$ ) of $\mathrm{RuO}_{2}$ films [11]. In this paper, we report applying green laser to the $\mathrm{RuO}_{2}$ films produced by this process to effectively sinter them into $50 \%$ denser ones with a low resistivity of $7.6 \times 10^{-5} \mathrm{~cm}$.

\section{Experimental procedure}

Ruthenium(III) nitrosylacetate $\left(\mathrm{Ru}(\mathrm{NO})(\mathrm{OAc})_{3}\right.$, Alfa Aesar), Monoethanolamine (MEA, Kanto Chemical), and propionic acid (PrA, Kanto Chemical) were used as received without further purification. $\mathrm{Ru}(\mathrm{NO})(\mathrm{OAc})_{3}$ was dissolved in enough PrA and MEA (molar ratio $\mathrm{MEA} / \mathrm{Ru}=2$ ) to form a $0.35 \mathrm{M}$ solution. The solution was stirred at $150{ }^{\circ} \mathrm{C}$ for 30 min under the ambient atmosphere and then cooled to room temperature and filtered.

The precursor solution was spin-coated on a glass substrate (OA-10) at $2000 \mathrm{rpm}$ for $25 \mathrm{~s}$., and then the coated substrate was dried at $150{ }^{\circ} \mathrm{C}$ for 5 min to remove the solvent. The film was annealed at $250{ }^{\circ} \mathrm{C}$ for 10 min under air. The films were irradiated with the green laser $(515 \mathrm{~nm})$ with a various energy densities (LAVA 100, Innovavent GmbH). 
The light absorption properties of the prepared thin films were investigated by UV-vis spectrophotometer (V-630, JASCO). The structures and density of the prepared thin films were characterized by X-ray diffraction (XRD) and X-ray reflectivity (XRR) analyses (X'Pert PRO MRD, PANalytical), and the surface morphologies were investigated by scanning electron microscopy (SEM; S-4100, Hitachi). The electrical resistivity of the films was measured at room temperature by the four-point probe method (Loresta-EP with TFP probe, Mitsubishi Chemical Analytech). Film thickness was evaluated by an electromechanical profiler (Alpha-Step, KLA-Tencor).

\section{Results and discussion}

Light absorption spectra of the thin films from the precursor solution annealed at $100-500{ }^{\circ} \mathrm{C}$ in air were examined (Fig. 1a). The absorption of the films increased rapidly at $250{ }^{\circ} \mathrm{C}$, which corresponds to the starting temperature of $\mathrm{RuO}_{2}$ formation from the precursor films, as indicated by XRD analysis (Fig. 1b). Thermal analysis in our previous study showed that the organic components in the precursor decomposed at $\sim 250^{\circ} \mathrm{C}$ [11]. (Detailed analysis of the structure and decomposition behavior of such Ru-amine complexes will be reported in a full paper that is in finalizing now.) These results suggest that $\mathrm{RuO}_{2}$ has stronger absorption in a wider range of wavelength than the precursor and that our GLA system having a laser wavelength of $515 \mathrm{~nm}$ may be utilized for $\mathrm{RuO}_{2}$ thin films.

The $\mathrm{RuO}_{2}$ thin films annealed at $250{ }^{\circ} \mathrm{C}$ were irradiated with a green laser under ambient conditions. XRD analysis of the $\mathrm{RuO}_{2}$ thin films irradiated with a green laser revealed that the crystal structure of the films depended on the energy density of the green laser. When the energy density was increased, diffraction lines became more intense and sharper as shown in Fig. 2. The XRD pattern of the $\mathrm{RuO}_{2}$ thin films before GLA shows a broad peaks at the positions of $\mathrm{RuO}_{2}(110),(101)$ and (211). In contrast, sharp diffraction lines were observed after GLA. Because the measurement conditions for XRD were same, this indicates GLA significantly improved the crystallinity of the $\mathrm{RuO}_{2}$ thin films.

The surface morphology of the $\mathrm{RuO}_{2}$ thin films before and after GLA was studied by SEM (Fig. 3). The microstructure of the films before GLA showed small $(\sim 30 \mathrm{~nm})$ granular crystallites. With increasing 
laser energy density in GLA, the crystallites grew larger $(\sim 100 \mathrm{~nm})$, accompanying sintering between grains. The joining between crystallites as a result of sintering was clearly visible after GLA at $0.7 \mathrm{~J} / \mathrm{cm}^{2}$. The microstructure evolution with the laser energy density is consistent with the change in XRD patterns.

We measured the resistivity and thickness of these films (Fig. 4). The resistivity of the films decreased with increasing energy density of GLA. The resistivities of the films before and after GLA at $0.7 \mathrm{~J} / \mathrm{cm}^{2}$ were $1.4 \times 10^{-3}$ and $7.6 \times 10^{-5} \mathrm{~cm}$, respectively, with more than one order decrease after GLA. The conductivity of the films irradiated with GLA was similar or superior to that of previously reported solution-processed $\left(2.9 \times 10^{-4} \mathrm{~cm}\right.$ annealed at $700^{\circ} \mathrm{C}, 700 \mathrm{~nm}$ thick $)[9]$ and vacuum-processed $\left(4.0 \times 10^{-5}\right.$ $\left.\sim 3.5 \times 10^{-4} \mathrm{~cm}\right)[3-8] \mathrm{RuO}_{2}$ thin films and only two times higher than that of the single crystal $\mathrm{RuO}_{2}(3.6$ $\times 10^{-5} \mathrm{~cm}$ ) [1]. In addition, the thickness of the films decreased as laser energy density of GLA increased, in correspondence to the resistivity change. The thickness of the film irradiated with GLA at $0.7 \mathrm{~J} / \mathrm{cm}^{2}$ was half $(\sim 40 \mathrm{~nm})$ of that before GLA. In fact, highly conductive ultrathin $(<50 \mathrm{~nm}$ thick $) \mathrm{RuO}_{2}$ films are difficult to be prepared by a solution process, but are commonly vacuum0deposited [3-8]. The decrease in thickness is attributed to significant densification of the film as well as possible partial vaporization of $\mathrm{RuO}_{2}$ in GLA treatment. The film density estimated from XRR analysis (uncertainty in data fitting $\sim \pm 0.2$ $\mathrm{g} / \mathrm{cm}^{3}$ ) was $4.2 \mathrm{~g} / \mathrm{cm}^{3}$ (pack density 0.6 ) before and $6.2 \mathrm{~g} / \mathrm{cm}^{3}$ (pack density 0.89 ) after GLA at $0.7 \mathrm{~J} / \mathrm{cm}^{2}$ (density of single crystal $\mathrm{RuO}_{2}: 7.0 \mathrm{~g} / \mathrm{cm}^{3}$ ). Therefore, GLA increased the density by $50 \%$, resulting in a dense nano-thick polycrystalline $\mathrm{RuO}_{2}$ film with high conductivity. The density is still smaller than typical values of vacuum-deposited films $\left(6.7-6.8 \mathrm{~g} / \mathrm{cm}^{3}\right)[3,5,8]$, and consistent with the presence of obvious pores between grains shown in the SEM image (Fig. 3). The superior conductivity is attributed to well joining of the grains by sintering in GLA.

The effects of the annealing temperatures of the $\mathrm{RuO}_{2}$ thin films before GLA were investigated. The films were prepared from the precursor solution and annealed at temperatures of $150-500{ }^{\circ} \mathrm{C}$ for 10 min in air. We examined the resistivities of the film before and after GLA at $0.7 \mathrm{~J} / \mathrm{cm}^{2}$ (Fig. 5a). The films annealed below $200{ }^{\circ} \mathrm{C}$ showed high electrical resistivity outside of the measurement limit $\left(\sim 10^{6}-10^{-7}\right.$ 
\%square, or $\sim 10-100{ }^{\circ} \mathrm{cm}$ for a $80 \mathrm{~nm}$-thick film). At annealing temperature $\geq 250{ }^{\circ} \mathrm{C}$, the resistivity of the films before GLA decreased gradually with increasing annealing temperature; this indicates crystalline $\mathrm{RuO}_{2}$ was formed but the sintering effect was minimal if only thermal annealing was used. $\left(\mathrm{RuO}_{2}\right.$ has crystallized upon decomposition of the precursor at $250^{\circ} \mathrm{C}$, as indicated in Fig. 1b.) The effect of GLA was confirmed in the films annealed at more than $250{ }^{\circ} \mathrm{C}$ : the resistivity decreased by one order or more (Fig. 5a). Once $\mathrm{RuO}_{2}$ has formed (at $\geq 250^{\circ} \mathrm{C}$ ), higher annealing temperature before GLA did not affect apparently the final resistivity (Fig. 5a) and crystallinity (shown by the XRD patterns in Fig. 5b) after GLA. Therefore, the highly conductive $\mathrm{RuO}_{2}$ film can be prepared at a low annealing temperature. The films annealed below $200{ }^{\circ} \mathrm{C}$ were ablated after GLA due to rapid decomposition of the precursor.

\section{Conclusion}

In summary, a highly conductive $\mathrm{RuO}_{2}$ thin film was prepared by applying greening laser annealing (GLA) to a low-temperature-annealed precursor film. First, $\mathrm{RuO}_{2}$ was produced at temperatures as low as $250{ }^{\circ} \mathrm{C}$ through the solution process, and then underwent GLA. GLA improved significantly the crystallinity of $\mathrm{RuO}_{2}$ and the film density, resulting in crystal growth and grain joining. The resistivity of $\mathrm{RuO}_{2}$ thin films annealed at $250^{\circ} \mathrm{C}$ and irradiated with GLA was $7.6 \times 10^{-5}{ }^{\circ} \mathrm{cm}$, which is similar or lower than that of the vacuum-processed samples $\left(4.0 \times 10^{-5} \sim 3.5 \times 10^{-4}{ }^{\circ} \mathrm{cm}\right)[3-8]$ and only $\sim 2$ times higher than that of the single crystal $\mathrm{RuO}_{2}\left(3.6 \times 10^{-5} \mathrm{~cm}\right)[1]$.

\section{Acknowledgements}

We thank Japan Science and Technology Agency for financial support of this work.

\section{References}

[1] Ryden WD, Lawson AW, Sartain CC. Electrical transport properties of $\mathrm{IrO}_{2}$ and $\mathrm{RuO}_{2}$. Phys. Rev. B 1970; 1: 1494-500.

[2] Kaneda T, Hirose D, Miyasako T, Tue PT, Murakami Y, Kohara S, Li J, Mitani T, Tokumitsu E, Shimoda T. Rheology printing for metal-oxide patterns and devices. J. Mater. Chem. C, 2014; 2: 40-9. 
[3] Reddy YKV, Mergel D. Structural and electrical properties of $\mathrm{RuO}_{2}$ thin films prepared by rf-magnetron sputtering and annealing at different temperatures. J. Mater Sci. : Sci: Mater Electron 2006; 17: $1029-34$.

[4] Yun DJ, Ra H, Jo SB, Maeng W, Lee S, Park S, Jang JW, Cho K, Rhee SW. Effects of postannealing process on the properties of $\mathrm{RuO}_{2}$ films and their performance as electrodes in organic thin film transistors or solar cells. ACS Appl. Mater. Interfaces 2012; 4: 4588-94.

[5] Han JH, Lee SW, Kim SK, Han S, Hwang CS, Dussarrat C, Gatineau J. Growth of $\mathrm{RuO}_{2}$ thin films by pulsed-chemical vapor deposition using $\mathrm{RuO}_{4}$ precursor and 5\% $\mathrm{H}_{2}$ reduction gas. Chem. Mater. 2010 ; 22: $5700-6$.

[6] Han JH, Lee SW, Kim SK, Han S, Lee W, Hwang CS. Study on initial growth behavior of $\mathrm{RuO}_{2}$ film grown bypulsed chemical vapor deposition: effects of substrate and reactant feeding time. Chem. Mater. $2012 ; 24: 1407-14$.

[7] Park SK, Kanjolia R, Anthis J, Odedra R, Boag N, Wielunski L, Chabal YJ. Atomic layer deposition of $\mathrm{Ru} / \mathrm{RuO}_{2}$ thin films studied by in situ infrared spectroscopy. Chem. Mater. $2010 ; 22$ : 4867-78.

[8] Park JY, Yeo S, Cheon T, Kim SH, Kim MK, Kim H, Hong TE, Lee DJ. Growth of highly conformal ruthenium-oxide thin films with enhanced nucleation by atomic layer deposition. J. Alloys Compounds 2014 ; 610: 529-39.

[9] Bhaskar S, Dobal PS, Majumder SB, Katiyay RS. X-ray photoelectron spectroscopy and micro-Raman analysis of conductive $\mathrm{RuO}_{2}$ thin films. J. App. Phys. 2001; 89: 2987-92.

[10] Tressler JF, Watanabe K, Tanaka M. Synthesis of ruthenium dioxide thin films by a solution chemistry technique. J. Am. Ceram. Soc. 1996 ; 79 : 525-9.

[11] Murakami Y, Tue PT, Tsukada H, Li J, Shimoda T. Preparation of ruthenium metal and ruthenium oxide thin films by a low-temperature solution process. Proceedings of the 20th International Display Workshops (IDW'13) 2013, pp1573-6. 
[12] Fujii M, Ishikawa Y, Ishihara R, Cingel JVD, Mofrad MRT, Horita M, Uraoka Y. Low temperature high-mobility InZnO thin-film transistors fabricated by excimer laser annealing. Appl. Phys. Lett. 2013; 102: 122107.

[13] Sugawara Y, Uraoka Y, Yano H, Hatayama T, Fuyuki T, Mimura A. A high-speed high-sensitivity silicon lateral trench photodetector. IEEE Electron Device Lett. 2007; 28: 395-7.

[14] Jiang J, Kuroki S, Kotani K, Ito T. Ferroelectric properties of lead zirconate titanate thin film on glass substrate crystallized by continuous-wave green laser annealing," Jpn. J. Appl. Phys. 2010; 49: 04DH14. [15] Foust DF, Rose JW, Balch EW. Method of forming ruthenium oxide films. US Patent US6,417,062 (2002) 


\section{Figure Captions}

Fig. 1. Absorption spectra (a) and XPD patterns (b) of thin films prepared from the precursor solution and annealed in air at various temperatures for $10 \mathrm{~min}$.

Fig. 2. XRD patterns for the $\mathrm{RuO}_{2}$ thin films annealed at $250{ }^{\circ} \mathrm{C}$ after GLA as a function of energy density.

Fig. 3. SEM images of the $\mathrm{RuO}_{2}$ thin films annealed at $250{ }^{\circ} \mathrm{C}$ after GLA as a function of energy density.

Fig. 4. Resistivity and thickness of the $\mathrm{RuO}_{2}$ thin films annealed at $250{ }^{\circ} \mathrm{C}$ after GLA as a function of energy density.

Fig. 5. (a) Resistivity of the $\mathrm{RuO}_{2}$ thin films annealed at various temperatures and treated with GLA at 0.7 $\mathrm{J} / \mathrm{cm}^{2}$, (b) XRD patterns of these films after the GLA. 
(a)

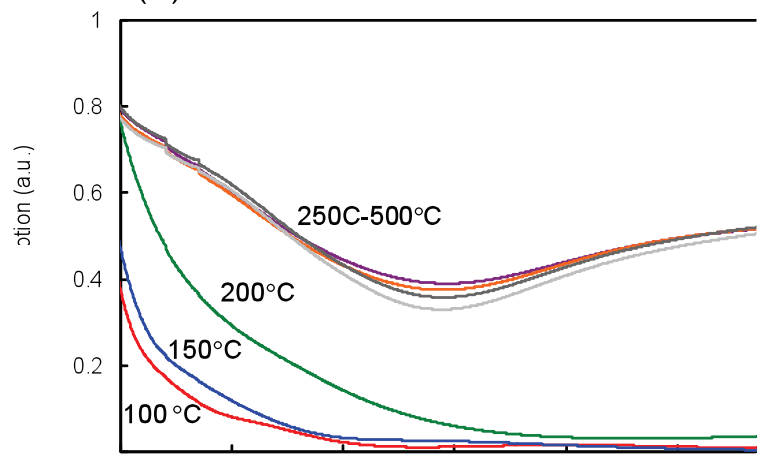

(b)

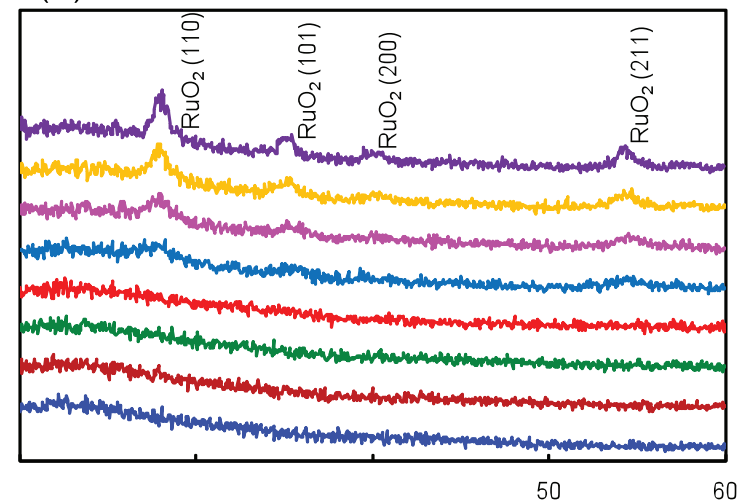

Fig. 1. Absorption spectra (a) and XPD patterns (b) of thin films prepared from the precursor solution and annealed in air at various temperatures for $10 \mathrm{~min}$.

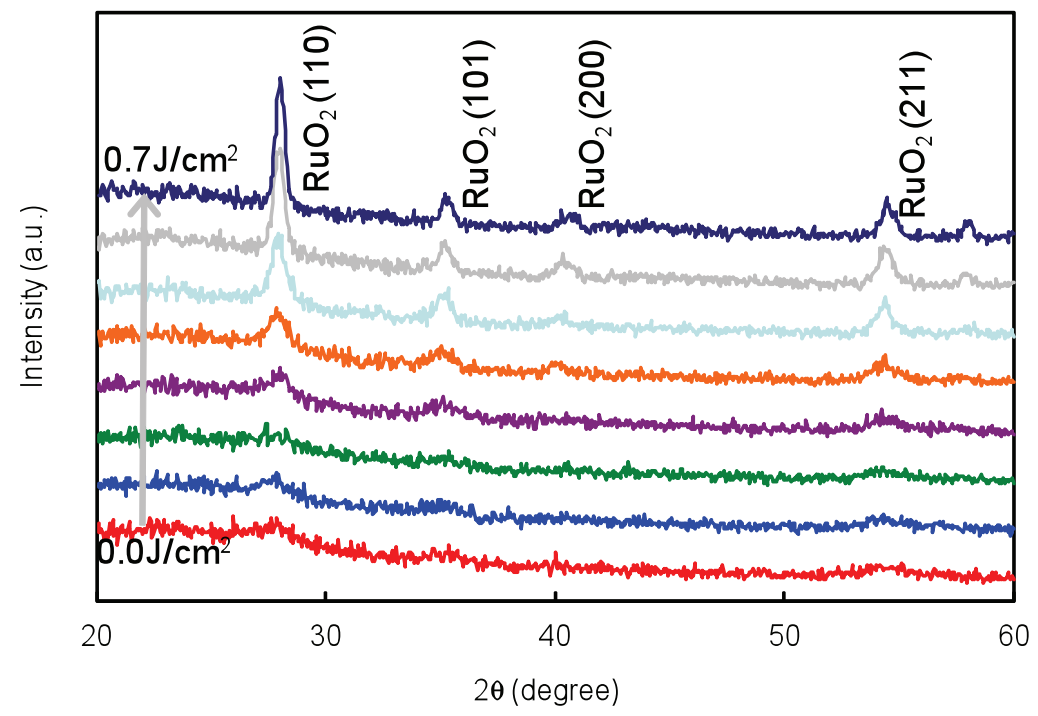

Fig. 2. XRD patterns for the $\mathrm{RuO}_{2}$ thin films annealed at $250{ }^{\circ} \mathrm{C}$ after GLA as a function of energy density. 

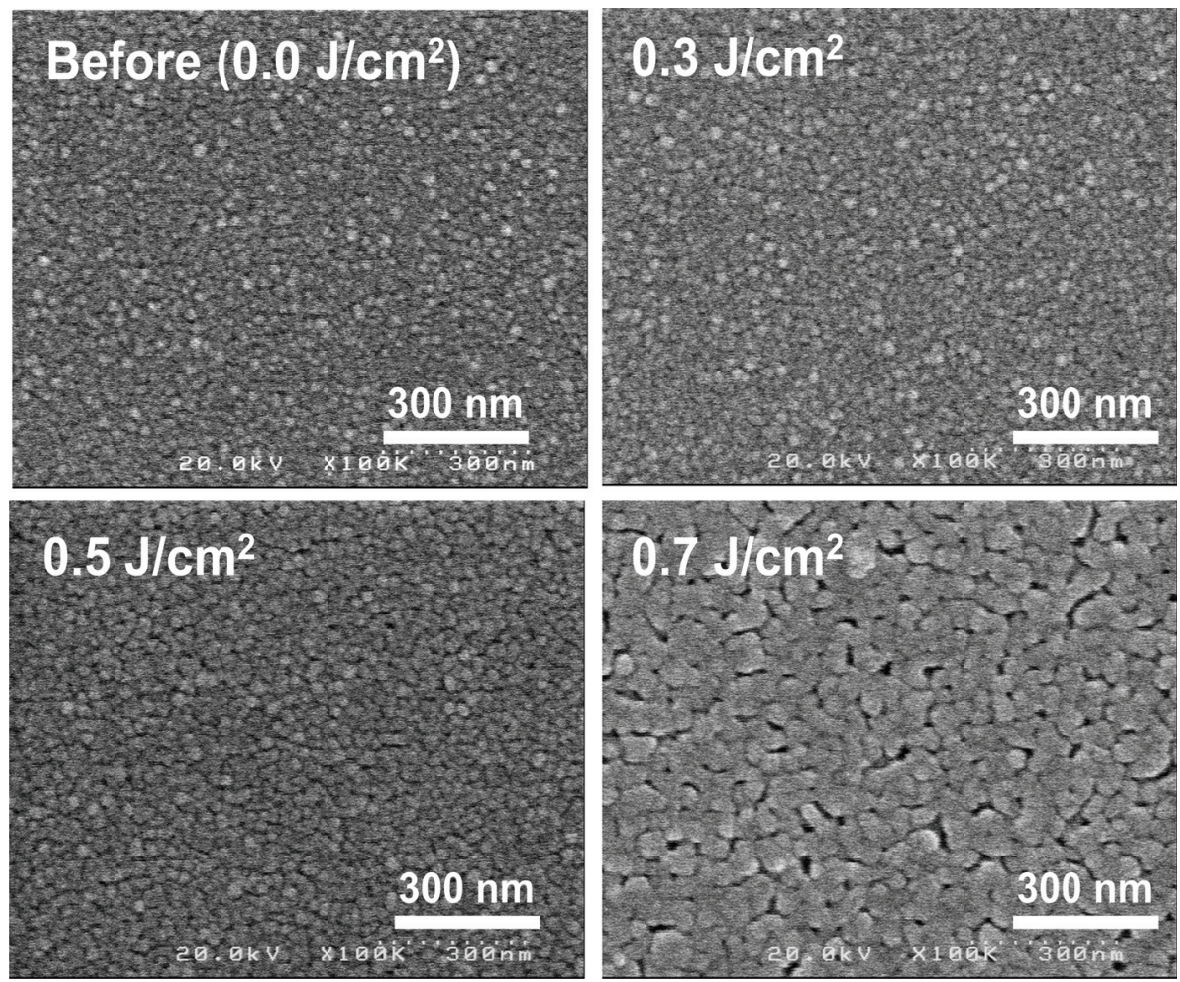

Fig. 3. SEM images of the $\mathrm{RuO}_{2}$ thin films annealed at $250{ }^{\circ} \mathrm{C}$ after GLA as a function of energy density.

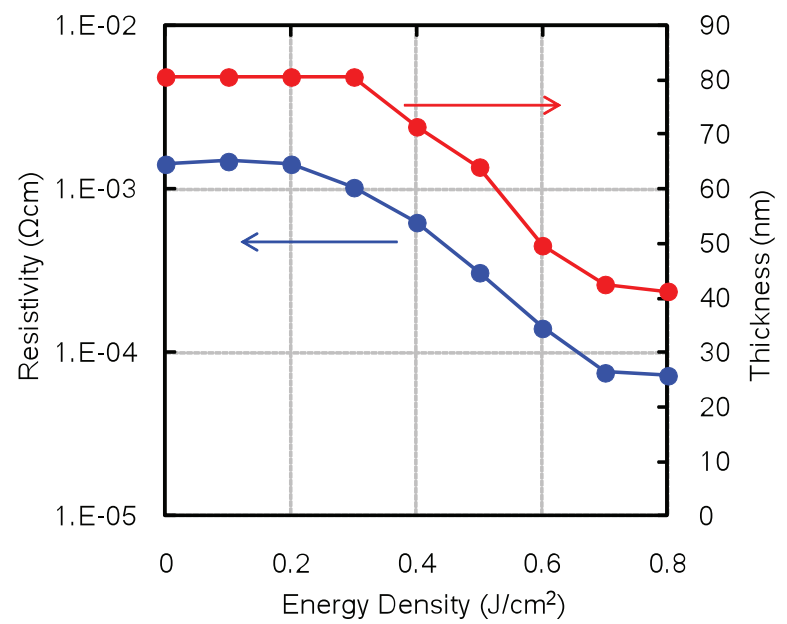

Fig. 4. Resistivity and thickness of the $\mathrm{RuO}_{2}$ thin films annealed at $250{ }^{\circ} \mathrm{C}$ after GLA as a function of energy density. 
(a)

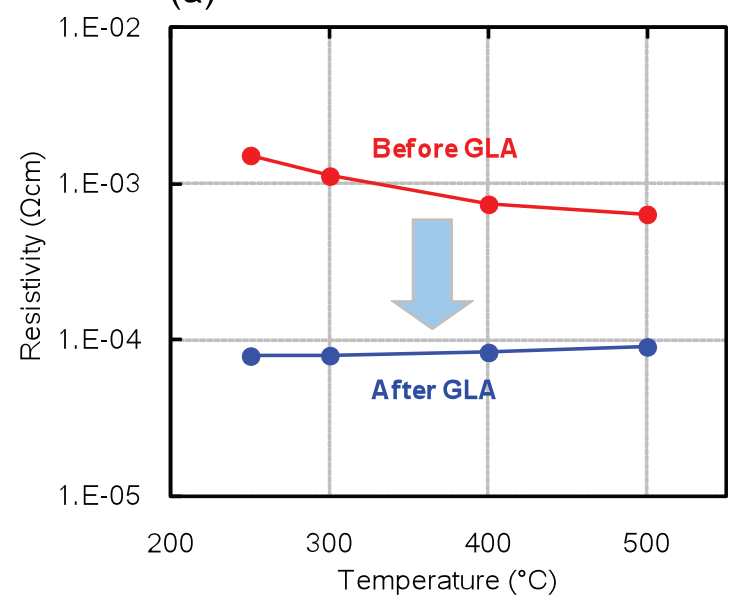

(b)

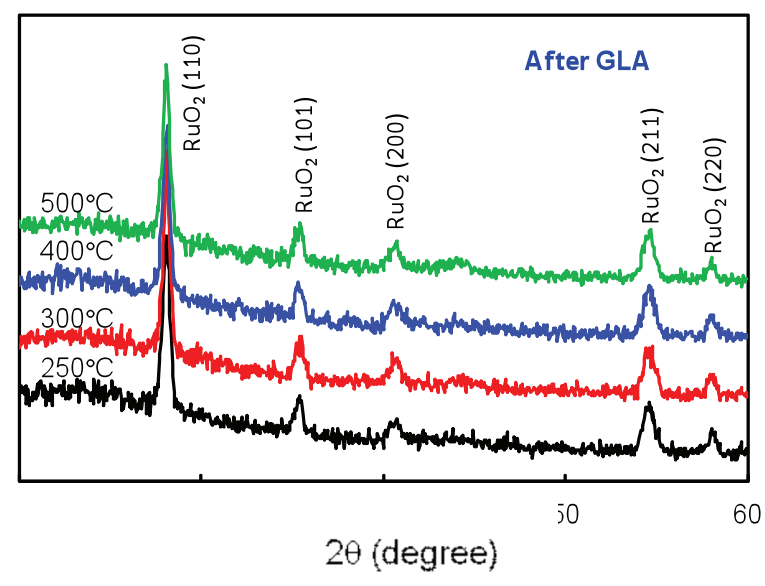

Fig. 5. (a) Resistivity of the $\mathrm{RuO}_{2}$ thin films annealed at various temperatures and treated with GLA at 0.7 $\mathrm{J} / \mathrm{cm}^{2}$, (b) XRD patterns of these films after the GLA. 


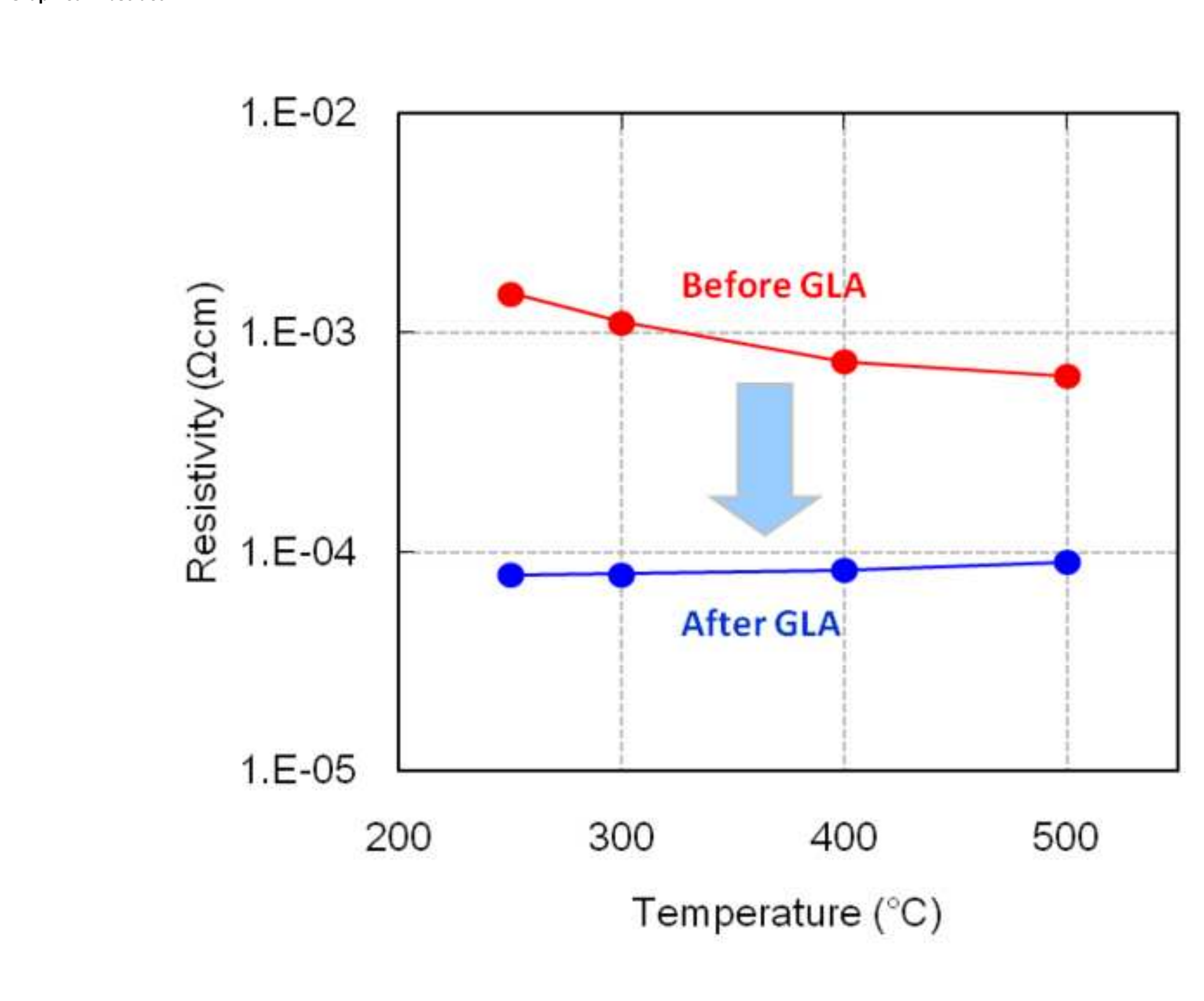

.

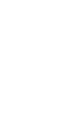

.

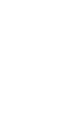

